\title{
Supportiveness of Existing Classroom Culture to the Implementation of Dialogic Teaching: Analysis of Teacher-Student Interaction in Physics Teaching and Learning
}

\author{
Hassen Worku ${ }^{1 \star}$, Mekbib Alemu ${ }^{2}$
}

${ }^{1}$ Dessie College of Teacher Education, Department of Physics Education, ETHIOPIA

${ }^{2}$ Addis Ababa University, Department of Science and Mathematics Education, ETHIOPIA

*Corresponding Author: haswor@gmail.com

Citation: Worku, H., \& Alemu, M. (2021). Supportiveness of Existing Classroom Culture to the Implementation of Dialogic Teaching: Analysis of Teacher-Student Interaction in Physics Teaching and Learning. Pedagogical Research, 6(3), em0100. https://doi.org/10.29333/pr/11062

\section{ARTICLE INFO}

Received: 9 Apr. 2021

Accepted: 23 May 2021

\begin{abstract}
This case study presents the analysis of teacher-student interaction in physics classrooms. The participants of the study were three physics teachers and 131 students from three upper primary schools (Grades 7 and 8) of Ethiopia. Data for the study were collected through observation of eight video recorded physics lessons. The analysis of videos indicated the teacher-student interaction in the existing physics classrooms were characterized by the transferring of factual knowledge; Initiation-Response-Evaluation (IRE) and Initiation-Discussion-ComputationResponse-Evaluation (IDCRE) types of interaction pattern; interactive/authoritative type of communication, evaluative feedback and use of low-level oral questions. Authoritative classroom communication, use of low-level questions, evaluative feedback; inappropriate intervention and support were the aspects of teacher-student interaction that seemed to influence the implementation of dialogic teaching as such type of classroom practices contradict the principles of dialogic teaching.
\end{abstract}

Keywords: classroom culture, dialogical teaching, Ethiopia, physics teaching and learning, primary school, teacher-student interaction

\section{INTRODUCTION}

Dialogic teaching has been suggested as an innovative pedagogical approach after a comparative study of primary educations in five countries: England, France, India, Russia and United States (Alexander, 2001). This comparative analysis produced the framework of dialogic teaching based on the principles of collective participation, reciprocal sharing of ideas, creating a supportive learning environment, and cumulative building of knowledge and understanding, and purposeful learning (Alexander, 2006).

In the last two decades, scholars directed their object of study toward dialogic pedagogy (e.g., Calcagni \& Lago, 2018; Lefstein \& Snell, 2014; Mercer \& Littleton, 2007; Rojas-Drummond et al., 2013).

Studies conducted in the field of classroom dialogue and dialogic teaching focused mainly on examining classroom discourse (Mortimer \& Scott, 2003; Muhonen et al., 2017), factors related to classroom dialogue (McNeil et al., 2016), developing strategies to evaluate dialogic practices in classroom (Howe, 2017; Mercer \& Howe, 2012), developing strategies to promote effective classroom dialogue (Gillies, 2017; Osborne, Erduran, \& Simon, 2004) and exploring benefits of classroom dialogue for students' learning (Aufschnaiter et al., 2007; Garcia \& Anderson, 2007; Osborne, 2012; Rojas-Drummond et al., 2017; Wilkinson et al., 2017).

Even if many studies recognised the various benefits of dialogic approach of teaching for students' learning (Aufschnaiter et al., 2007; Garcia \& Anderson, 2007; Osborne, 2012), its implementation in classrooms is difficult. Literature recognized that facilitating the philosophy of dialogue into a specific model of classroom practices is not straight forward as the situation of the current classroom conflicts against the critical feature of dialogue (Lefstein \& Snell, 2014). It was also suggested that building a classroom environment that supports dialogical teaching is necessary for the successful implementation of dialogic teaching (Boyed \& Markarian, 2015; Lyle, 2008).

Dialogic approach to teaching was introduced to Ethiopian education in 2015 by a project named "Transforming the Pedagogy of Science, Technology, Engineering and Mathematics (STEM) Subjects" (TPSS). The introduction of dialogic teaching into Ethiopian education aimed to transform the pedagogy of STEM subjects in general and physics subject in particular. The concern was initiated because of the potential benefit of the approach to enhance students' understanding through involving them in a discussion, analysing and evaluating ideas of others, and justifying of claims (Alexander, 2006) unlike the didactic approaches that 
dominantly employed in science classrooms in Ethiopia (Abdela \& Kassahun, 2010; Daniel, 2004; Derebessa, 2006; Mekbib et al., 2019). The project implemented the approach and observed its effect on the teaching and learning of physics in teacher education colleges and upper primary schools (grade 5 to 8). Even if the students who were taught by the dialogic approach have performed more than those taught by the 'traditional' approach as verified by literature (Mekbib, 2015; Mekbib et al., 2019; Tadesse, 2017), their improvement was not convincing. So, it is important to examine the constraints to the implementation of dialogic teaching in Ethiopian classroom contexts.

Although dialogical teaching has been recognised as a pedagogical approach that enhances students' understanding through involving students in meaningful classroom dialogue discussion (Alexander, 2006), it was implemented in Ethiopia without taking the impacts of the existing classroom culture into consideration. Existing classroom culture in this study refers to the interaction between teacher and students, and among students in didactic classrooms of physics teaching and learning. Therefore, by recognizing the role of classroom culture in dialogic teaching, analysis of teacher-student interaction was made to explore the existing classroom culture of physics teaching and learning in upper primary schools, to determine the supportiveness of existing classroom culture to dialogic teaching approach and to identify the aspects of teacher-student interaction that influence implementation of dialogic teaching. Identifying these aspects is important in that it discloses issues related to teacher-student interaction that should be considered in teacher professional development training on dialogic teaching.

\section{Aims and Questions}

This study aims to explore the nature of the teacher-student interaction in physics teaching and learning, and to determine the aspects of the interaction that influence dialogic teaching in classroom setting. To achieve the purposes, the following questions are addressed.

1. What are the characteristics of teacher-student interactions in physics classrooms of upper primary schools?

2. What aspects of teacher-student interactions constrain the implementation of dialogic teaching in physics classrooms?

\section{Analytic Framework}

The framework used to analyse the teacher-student interaction was the approach developed by Mortimer and Scott (2003). The framework consists of five aspects of teacher-student classroom interaction including "teaching purposes, the content of the interaction, communicative approach, patterns of discourse and teacher interventions" (p. 25).

The teaching purpose is concerned with the purposes of teaching at various phases of the lesson with respect to the content of a lesson being taught. The content of the interaction aspect is concerned with the contents addressed by utterances of students and teachers with respect to the lesson being taught. The analysis of content of interaction focussed on exploring whether the teacher's and students' utterances are scientific or everyday types of social language, each of which can further be classified as 'description', 'explanation' and 'generalization'. The communicative approach focused on whether multiple points of view were encouraged in the lesson (authoritative/dialogic dimension) or not and whether students were involved in the development of ideas or not (interactive/non-interactive dimension). The patterns of discourse focused "on the simple, but distinctive patterns of interaction that emerge between teacher and students during ongoing classroom talk" (p. 27). The teacher intervention was the aspect of teacher-student interaction which was concerned with the various ways in which teachers intervene in the development of concepts and meaning-making at different phases of the lesson.

\section{Research Context}

The study was conducted on three upper primary schools of Dessie town, the main city of South Wollo administrative zone in Amhara regional state, Ethiopia. Data were collected from grades 7 and 8 physics classroom using video recorders. The classrooms were recorded with two digital video cameras. While the first camera (fixed camera) recorded the whole class, the second camera (movable camera) recorded the practices of the teachers. Since one of the cameras was fixed, only the corresponding author of this study was involved in recording the classrooms.

A total of eight lessons which were taught by the 'conventional' teaching approach (the teachers' usual methods of instruction) were recorded, transcribed and analysed to characterize the teacher-student interaction. Four lessons from grade 7 in school 1 (lesson topics: Work, energy, mechanical advantage, and efficiency), two lessons from grade 8 in school 2 (lesson topics: pressure and transfer of heat) and two lessons from grade 8 in school 3 (lesson topics: pressure and liquid pressure) were considered in the analysis.

The participant teachers in the three schools were graduated from teacher education colleges with a diploma. Their experience of teaching physics in grade 7 and 8 ranges from 7 years to 15 years. The teachers were briefed on the purpose of the study and asked their agreement to be participant for the study prior to the classroom recording. A total of 131 students, whose ages ranges from 13-18 years were involved in the study. The average number of students in a class range from 40 to 44 . Since the change of the medium of instruction begins to occur in grade seven in the education system of Amhara region, classroom communication in the upper primary schools is a kind of Amharic and English mix (Mekbib et al., 2019).

\section{Research Methods}

This study is a case study which described a single unit (ie, teacher-student interaction in physics classes) in its natural context. Observation of classroom teaching and learning process with the help of recorded videos was the instrument used to collect data from three physics teachers in three upper primary schools (grades 7 and 8). The teacher-student interactions in the recorded videos were transcribed and translated into English for the purposes of analysis. The translation was made because the teachers and students used an English-Amharic (mother tongue) mixed type of language throughout their interaction. 
Table 1. Code definition table for categories of content of interaction

\begin{tabular}{ll}
\hline Categories of content of interaction & Definitions \\
\hline Everyday & Use of everyday type of social language to describe and explain ideas \\
\hline Scientific & Use of scientific language to describe and explain ideas \\
\hline Description & Providing an account of a phenomenon in terms of its constituents or characteristics \\
\hline Explanation & Use of some form of theoretical model or mechanism to account for a specific phenomenon \\
\hline Generalization & Making a description or explanation that is independent of any specific context \\
\hline Theorical & Explanation of a phenomenon based on observed features \\
\hline
\end{tabular}

Table 2. Code definition table for communicative approaches

\begin{tabular}{ll}
\hline Communicative approaches & Definitions \\
\hline Interactive & Both students and teachers are actively involved in classroom interaction \\
\hline Non-interactive & Classroom interaction is dominated by teachers \\
\hline Authoritative & Classroom interaction prohibits the building of diversified views \\
\hline Dialogic & Classroom interaction is supportive of making different view points \\
\hline
\end{tabular}

The teacher-student interaction was analysed qualitatively based on its five features including teaching purposes, content of the interaction, communicative approach, patterns of discourse, and teacher interventions to characterize the nature of the existing teacher-student interaction. The transcribed teacher's and students' talks were analysed and interpreted within the context of their interaction. Consequently, a word, a phrase, or a statement was considered as a unit of analysis as each can transfer meanings based on the context of the dialogue.

Pre-defined codes were used to analyse the contents of interaction and communication approaches (Mortimer \& Scott, 2003). To examine the content of interaction, classroom talks were categorized into everyday-scientific, description-explanationgeneralization and empirical-theoretical dimensions. Table 1 presents the various categories of contents of interaction and their respective definitions.

Similarly, the analysis of the communicative approaches was made based on "two dimensions: Interactive/non-interactive and dialogical/authoritative" (Mortimer \& Scott, 2003, p. 33). These communication approaches and their descriptions are presented in Table 2.

On the other hand, the teaching purposes, patterns of classroom discourse, the kinds of teacher interventions and the functional categories of teachers' oral questions were analysed inductively. Finally, the findings obtained from the analysis were discussed with respect to the principles and characteristics of dialogic teaching to determine the aspects of the existing teacherstudent interaction that influence the practices of the teachers in dialogic classroom setting.

The transcription of the videos was carried out by the corresponding author of the study. However, to check the reliability of the transcriptions and that of the functional classification of the teacher's oral questions, an inter-coder agreement was computed on one sample lesson. The consistency of the coders on the transcriptions and classification of the teachers' questions were found to be in the accepted range as the percentages of agreement between the coders was $91.7 \%$ for the transcription and the Cohen's Kappa coefficient was 0.898 for the classification of the teachers' oral questions (Graham, Milanowski, \& Miller, 2012).

\section{RESULTS}

\section{Teaching Purposes}

When the teaching and learning process progresses, different teaching purposes are addressed and each purpose relates to a particular phase of a lesson. In the first phases of the lessons, what was commonly observed in the schools was starting teaching new lessons by asking questions from the previous lessons. For example, the teacher in school 1 asked questions such as "What is force?", "What does velocity ratio mean?" and "What does efficiency mean?". Similarly, the teacher in school 2 asked questions such as "What is force?" and "What is pressure?". The same pattern of questioning was also observed with the teacher in school 3.

Teachers may ask questions at the beginning of a new lesson for different purposes such as for diagnostic assessment, for making connection between previous knowledge and knowledge of a new topic or for making students ready for a new lesson. However, the purposes of the teachers' questions in the observed lessons seemed to only remind what has been taught in the previous lesson rather than creating a link between knowledge in the lessons. This kind of incidences was observed for the topics that were consecutive where describing their relationships was essential. This situation is exemplified by the following transcription of teacher's explanation after a student replied to the question "What does velocity ratio mean?" in school 1.

Teacher: Exactly. Velocity ratio can be defined as the ratio of distance moved by what? [] distance moved by the effort to the distance moved by the load. That means SE over what? SL [by writing VR $=\frac{S E}{S L}$ ]. Ok, today we will discuss about efficiency [writing on the board] ...To define efficiency, first, we explain about work input and work output...

In the above incidence, students were taught in the previous lesson about velocity ratio, and the topic of the current lesson was "efficiency", which is related to the concept of "velocity ratio". Even if efficiency of a machine (the current lesson) can be described in terms of "velocity ratio" (the previous lesson), the teacher described efficiency with respect to other concepts 
"workout put and work input", something not mentioned in the revision. If the teacher had defined efficiency in terms of velocity ratio, the students would have the opportunity to recognize the relationship between efficiency and velocity ratio so that the construction of knowledge would be smooth.

Besides the revision of lessons, the first phases in the observed lessons were intended to introduce new topics. The introductions of the new lessons were made mainly through providing definitions of concepts, describing mathematical relationships among concepts and sometimes by asking questions. The following are some pieces of transcriptions of the teachers' talks in the three schools that exemplify how they introduced new lessons where the words under the quotation were the topics of the lessons.

\section{School 1}

Teacher: ..."work" is the product of force and distance.

Teacher: "Energy" is the ability to do work.

\section{School 2}

Teacher: ..."pressure" is defined as force per unit area

\section{School 3}

Teacher: ..."pressure" is force per unit area

In the second phases of the lessons, students were provided with tasks to be done in groups. In most of the lessons, the questions in the tasks were numerical, which needed some kind of computations. When the students were doing tasks in group, teachers were observing the students' group discussions, and sometimes they were intervening in the discussion through asking questions. Consequently, the purposes of teaching in the second phases were analyzed based on the interaction of the group members with teachers.

The teachers' oral questions, which encouraged interaction during the group work sessions, mainly focussed on procedures of solving numerical problems. Procedural questions like "What are you given?", "How did you do?" and "What is required?" were frequently asked by the teachers. Furthermore, questions that needed computation such as "how much is the product of ...?" were also frequently asked. For instance, from a total of 21 questions asked to students during the group work session of one lesson, 15 questions (71\%) were of a kind of the above questions. Even, the other six questions (e.g., "How much is the given force?") were also related to solving numerical questions. Look at the following pieces of transcription that represent the teacher-student interaction with three different groups in school 1 when the students were doing the group work activity.

\section{Exchange 1}

Teacher: Are you listening to her? What did she do first? [Looking at other students]

Students: Given quantities.

Teacher: After given quantities []

Student: Required.

Teacher: What is asked?

Student: Work.

\section{Exchange 2}

Teacher: Ok. What did she identify? [looking at another student].

Students: Given quantities.

Teacher: Ok. Which quantities are given in the question?

Student: Force and displacement.

Teacher: Ok. Force and displacement are given. How much is the force?

Student: Three hundred.

Teacher: Ok. After that [] 
Student: We are asked the force. So, we use the formula...

\section{Exchange 3}

Teacher: How did he do? [Asking one of the students]

Student: First, he identified the given quantities.

Teacher: Ok. Which quantities are given?

Student: Force.

Teacher: Ok. How much is the force?

Student: The force is three hundred.

The questions asked to all the groups were in a manner to help the students develop skill of solving numerical problems, which tended to a "Given-Required-Solution" procedure. The questions focused on what students should do when solving a given numerical problem. Except encouraging the students to come up with the correct numerical answers to the questions, the teachers' attempts to check the students' understanding of the problem so that they could relate what they were solving with the context of the problem were weak. In some incidences, the teachers demonstrated explicitly that their focus was on the final answers (numerical values) rather than the meaning behind doing the problem. For example, the teacher in school 3 was observed to say "...This is not the answer. First, change this mass, after that change the length then finally change the width" without critically evaluating how the students arrived at that answer.

The third phases were the sessions in which the groups often shared the results of their discussion to the whole class. The sharing of ideas to the whole class was carried out mainly in two ways: either one student from the groups showed what they did to the whole class, or the teachers themselves solved the problem or summarized the discussion.

The analysis the teacher-student interaction, in general, indicated that the purposes of teaching were different at different points of the lessons. The purposes of teaching in the first phases seemed to revise the previous lessons mainly by asking questions and introduce the new topics mainly through defining facts and concepts. The purposes of teaching in the second phase (group work session) were found to depend on the nature of group work activities. Since most of the questions in the group work activities were numerical problems, the intention of teaching in this phase was tended toward developing the students' problem-solving skills. Moreover, the non-numerical questions in the group work activities were also in the form of "what questions" which require only describing facts. In the third phase (the sessions after the group work), the purposes of teaching were summarizing and sharing ideas.

\section{Content of Interaction}

This feature of teacher-student interaction is concerned with the contents addressed by the teacher's and students' utterances. The content of the interaction was analysed based on three dimensions including "Everyday-scientific; Descriptionexplanation-generalization and Empirical-theoretical dimensions" (Mortimer \& Scott, 2003, p. 26) in which their descriptions are as shown in Table 1.

It is possible to recognize from the previous analysis that questioning was the core strategy employed by the teachers to facilitate the classroom interactions in all phases of the lessons. Teachers used questions to revise lessons, to facilitate group work discussions, and to check the students' knowledge and understanding. Hence, the quality of students' utterances could be determined by the nature of teachers' questions. For example, if a teacher asks high cognitive demand questions such as that require reasoning, evaluating, comparing and contrasting, students will be engaged in a constructive dialogue through the effort they made to respond to the questions. However, in this study, the teachers' questions were not as such challenging and they required recalling of knowledge from previous lessons or textbook and simple knowledge of computation. Consequently, the students' responses were forced towards the use of physics terms and phrases that tilted towards the latter pole with respect to the everyday-scientific dimension. The following sets of questions were asked at different points of the lessons by the teachers in the three schools. The students' responses to these questions exemplify the language expectations and content of the students' utterances concerning the description-explanation-generalization dimension.

\section{School 1}

1. What is work?

2. What is a scalar quantity?

3. What is energy?

\section{School 2}

1. What is force?

2. What is the SI unit of pressure?

3. What is temperature?

\section{School 3}

1. What is temperature? 
2. How much kilogram would one hundred grams be?

3. How do you calculate density?

Besides asking such lower-order thinking demanding questions, the teachers mostly expressed concepts in terms of their relationships with other concepts and explained how the questions could be calculated rather than focusing the basic ideas behind the concepts. The following are examples of descriptions of concepts in relation to other concepts.

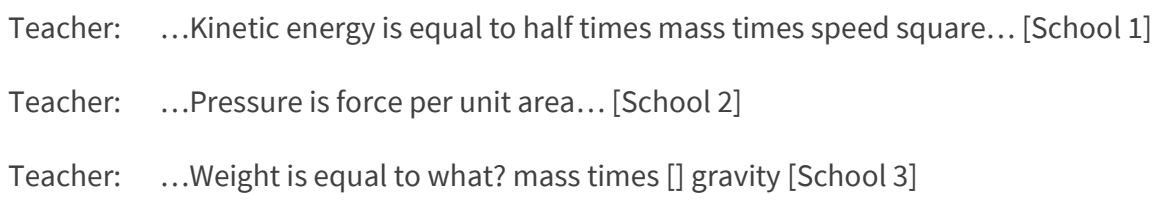

The numerical nature of the questions in the group work activities made the utterances of the teachers and students to be focussed on the expression of procedures of solving numerical problems. During the second phase of the lessons, the central role of the teachers was facilitating the group discussion by asking questions such as "What is given?", "What is required?", "What do you do first?" whose answers were brief and straightforward.

The analysis of the classroom interaction, in general, showed that the contents of the utterances of the teachers and students were scientific than every day, descriptive than explanation and generalization. However, their utterances could not be classified with respect to the empirical-theoretical dimension, because the students and the teachers were engaged more in describing factual knowledge found in the curriculum in the form of definitions and relationships between concepts rather than providing explanation and justification. The teachers did not manage the teaching and learning processes and encouraged the students to explain phenomena or concepts using reasons or evidence since most of the questions that the teachers asked were low-level questions.

\section{Communicative Approach}

Regarding classroom communication, the analysis of the data indicated that authoritativeness was reflected frequently at different points of the lessons. It was reflected in the questions asked by the teacher. Both the oral and written questions used in the classrooms were not purposefully designed to elicit different viewpoints, and were not able to encourage critical thinking. Since the teachers' questions were at the description level, the students' responses to the questions were short and precise, ranging from a single word or number to statements. Most of the oral questions raised by the teachers demanded the students to provide definitions of physics terms and concise answers. Questions like "What is energy?", "What is pressure?" and "What is the SI unit of force?" were frequently posed by the teachers. The numerical nature of the group work activities also led the group work discussions to be focused on manipulation of numbers and getting the final numerical answer of the questions rather than understanding the knowledge behind the computation.

The authoritative nature of the classroom interactions was also observed in the teachers' reactions to the students' responses. It was frequently observed that teachers were ignoring the students' responses and looked for another response, or immediately providing the answers to the questions after one or two students had attempted. This could be exemplified by the following transcription of a piece of dialogue in school 1 (Topic: kinetic energy).

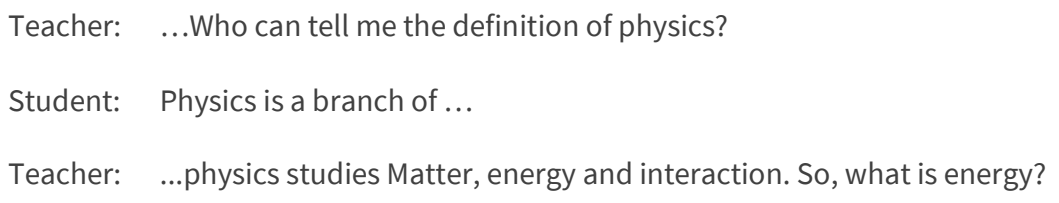

In the above excerpt, it can be seen that the student started to respond to the question in a way she thought was correct. Nevertheless, the teacher did not allow the student to complete her answer when he noticed that the students' answer was not worded as the teacher expected the right answer. Similarly, in the following transcription, the teacher in the same school ignored the students' response (turn 4) without attempting to know why the student said in that way and without providing the student with the opportunity to give his justification.

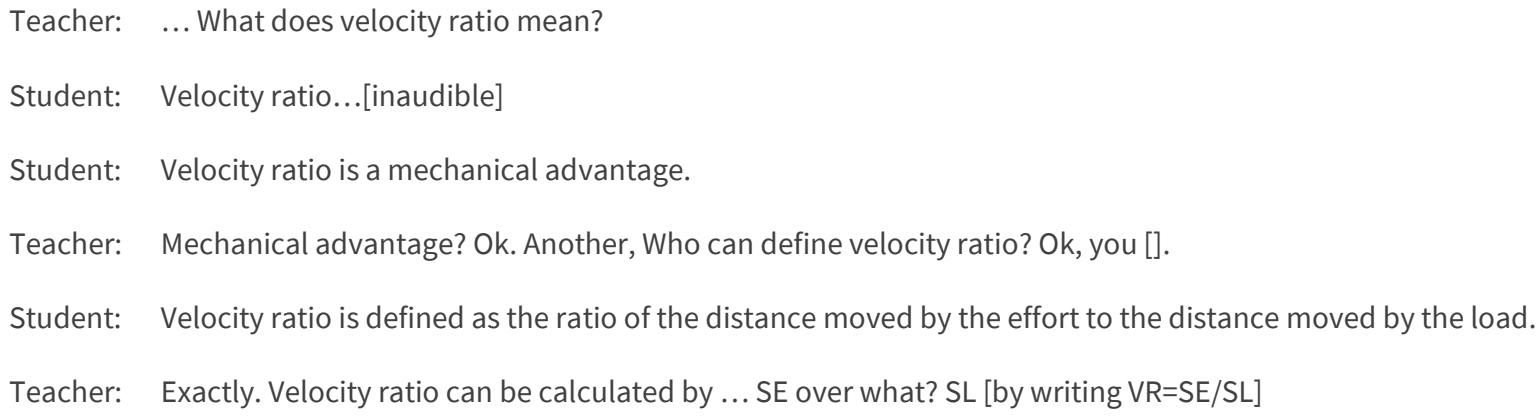

Here, it seems that there is something in the teacher's mind that he wanted to hear from the students, such as the right formula to compute the velocity ratio. That is why he swiftly moved from the first to the second, then to the third student until the students' 
Table 3. Sample I-R-E interaction pattern from CS1 (topic: energy)

\begin{tabular}{cccc}
\hline Turn number & Speaker & Utterance/talk & Label \\
\hline 2 & Teacher & ... what is energy? & \\
\hline 3 & Student & Energy is the ability to do work. & Response \\
\hline 4 & Teacher & Yes. Energy is the ability to do work. & Acknowledgment \\
\hline 5 & Teacher & What is matter? & Initiating \\
\hline 6 & Student & Matter is anything that occupies space and... \\
\hline 7 & Teacher Exactly, matter is anything which occupies space and has weight. Acknowledgment \\
\hline
\end{tabular}

responses were in harmony with that in the teacher's mind. The answer given by the first student was not known due to her inaudible voice, but the teacher neither gave a chance for the student to re-state the answer with audible voice nor ask another nearby student to repeat what she has said. The teacher went on with the error answer with the second and correct answer of the third student without allowing other students to evaluate and reflect on these answers.

The imposition of the teachers to lead the students' perspectives towards the teachers' perspective was another cause for the existence of authoritative classroom communication. This situation can be exemplified by the following piece of transcription which was taken from classroom interaction of school 2 (topic: transfer of heat).

Teacher: ... Thank you... Why did the answer become negative?

Student: If We subtract $100^{\circ} \mathrm{C}$ from $40^{\circ} \mathrm{C}$, the result will be negative.

Teacher: Another student. Who can help her? Why did it became negative $60^{\circ} \mathrm{C}$ ?

Student: Because the final temperature is $40^{\circ} \mathrm{C}$ and the initial temperature is $100^{\circ} \mathrm{C}$. So, subtracting $100^{\circ} \mathrm{C}$ from $40^{\circ} \mathrm{C}$ gives $-60^{\circ} \mathrm{C}$.

Teacher: Because the object becomes cold [by indicating the word 'cools' on the board].

In this interaction, the teacher asked the students why the calculated answer became a negative number. Two students reflected their reasons. The first student said it is because, "if we subtract $100^{\circ} \mathrm{C}$ from $40^{\circ} \mathrm{C}$, the result will be negative" (turn 19). Since the teacher was not satisfied with the answer, he gave a chance to another student. The second student replied "The final temperature is $40^{\circ} \mathrm{C}$ and the initial temperature is $100^{\circ} \mathrm{C}$. So, subtracting $100^{\circ} \mathrm{C}$ from $40^{\circ} \mathrm{C}$ gives $-60^{\circ} \mathrm{C}$ " (turn 21). Even if the responses of both students were correct, the responses were not in line with the answer in the teacher's mind. Finally, the teacher explained his reason for the negative answer that it was because "heat is lost form the object" (turn 22).

The analysis of the classroom communication, in general, indicated that the observed classrooms in the three schools were interactive as a result of the students' involvement in answering the teacher's oral questions. However, due to the nature and apparent purposes of the questions, students were limited to giving the textbook answers in a language the teacher thought right. In all lessons, teachers did not present alternative ideas and nor did he allowed the students to express and defend their ideas publicly. The exclusive focus on the physics curriculum truth and lack of proper reactions to students' responses on the part of the teacher made the teacher-student communication authoritative.

\section{Patterns of Discourse}

Patterns of discourse refer to the distinctive pattern of teacher-student interaction observed in the teaching and learning of the lessons. From the analysis of the data, two distinct patterns of discourse were mainly recognized as the consequence of the frequently asked teacher's questions and the respective responses from the students. The first pattern of discourse was a type of an Initiation-Response- Evaluation (I-R-E) in which the teachers posed oral questions, the student responds, and the teachers react to the responses in the form of evaluation. Table 3 presents a piece of transcription of a classroom video from school 1 that exemplifies the I-R-E type of interaction pattern.

As shown in Table 3, the reaction of the teacher to the student's response was judgemental. Correct responses were acknowledged and praised by the teacher. The teachers' acknowledgements were reflected in the interaction by words such as "Exactly", "Yes" and "Ok" following the students' responses. Another way of a positive evaluation by the teachers was observed when they repeated what students have said (e.g., turn 4, turn 7). A similar interaction pattern was frequently observed in all classrooms of the three schools.

Because the teachers were mostly asking students whose hands were raised, and these students probably knew the answer of the questions, incorrect responses from the students were observed rarely in the interaction. This was represented by the dotted line in Figure 1. The teachers' reactions to the incorrect students' responses were letting another student answer the question and providing the answer themselves. 


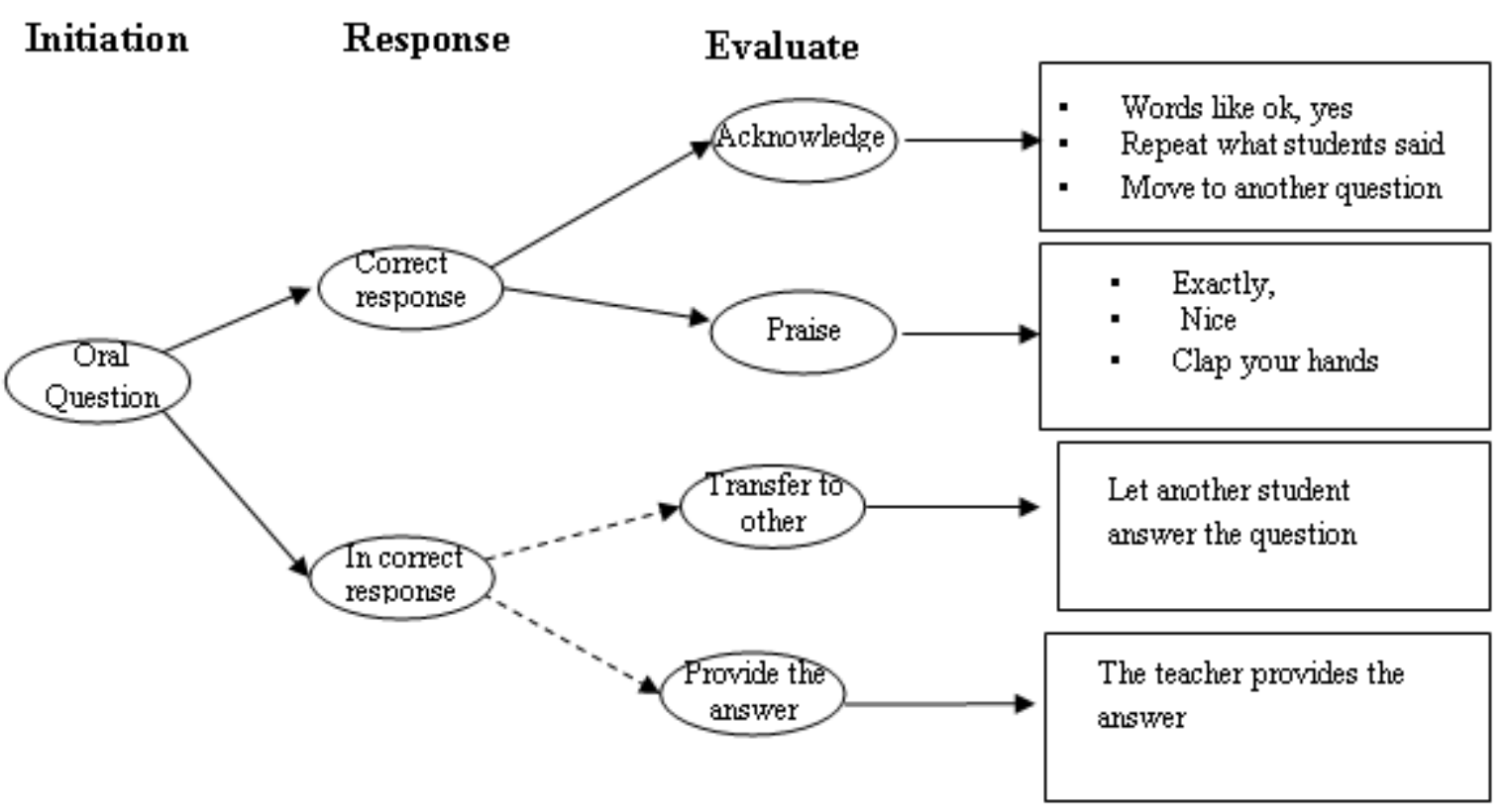

Figure 1. Interaction Sequence Initiated by Oral Questions

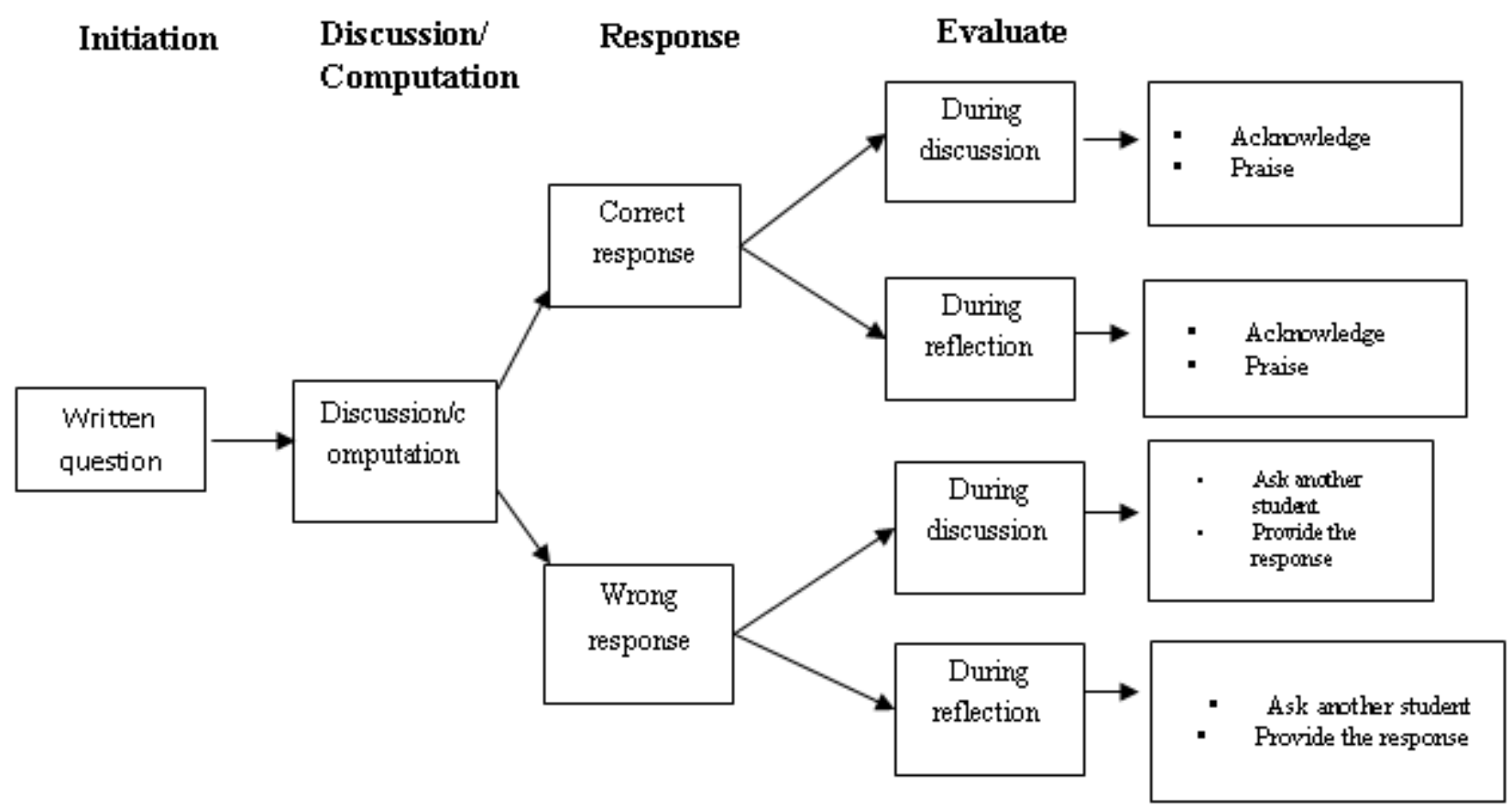

Figure 2. Interaction Sequence Initiated by Written Questions

In the interaction pattern initiated by written questions, additional turns were created between the initiation and the response turns of the I-R-E pattern. In this new turn, the students engaged in discussion and/or computation before they respond. As a result, an Initiation-Discussion-Computation-Response-Evaluation (I-D-C-R-E) pattern of discourse was created. In the I-D-C-R-E pattern of discourse, the evaluation was made during both the group discussion and reflection time. Similar to the I-R-E interaction pattern, correct responses in this interaction sequence were acknowledged or praised by the teacher and for incorrect students' responses, the teachers' reactions were either transferring the question to another student or providing the answer themselves. Figure 2 represents the interaction sequence of I-D-C-R-E pattern.

\section{Teacher Interventions}

Teacher intervention can be thought of the various ways in which the teacher intervenes in the development of concepts and meaning-making. Various interventions might be made at different points of a lesson based on what the teacher intended to do with respect to the topic being taught. Teachers' interventions play a crucial role in engaging students in the classroom interaction, thereby supporting their learning. This may be achieved using different scaffolding strategies such as prompting students to reflect their perspectives, justify their claims, and evaluate the perspectives of others. However, in this study, the teachers' 
Table 4. Functional Categories of Teacher's Oral Questions, their Examples and Frequency of Questions

\begin{tabular}{|c|c|c|c|c|}
\hline Category of questions & Code & Description & Examples & $\%$ \\
\hline Descriptive question & $\mathrm{DQ}$ & $\begin{array}{l}\text { Questions that require students to define, describe or } \\
\text { mention concepts or phenomena. }\end{array}$ & $\begin{array}{l}\text { - What is pressure? (CS3) } \\
\text { - Who can define pressure? (CS2) }\end{array}$ & $37.5 \%$ \\
\hline $\begin{array}{l}\text { Leading } \\
\text { question }\end{array}$ & LQ & $\begin{array}{l}\text { Questions posed when the teacher is explaining or } \\
\text { lecturing in the whole class session for the purpose of } \\
\text { facilitating his teaching. }\end{array}$ & $\begin{array}{l}\text { - ... can be calculated by distance moved by } \\
\text { what? (CS1) } \\
\text { - Liquid is what? (CS3) }\end{array}$ & $6.5 \%$ \\
\hline Procedural question & $P Q$ & $\begin{array}{l}\text { Questions asked in relation to procedures and other } \\
\text { aspects of computing numerical questions. }\end{array}$ & $\begin{array}{l}\text { - What did she do first? (CS1) } \\
\text { - What are you given? (CS1) }\end{array}$ & $13 \%$ \\
\hline $\begin{array}{l}\text { Confirmational } \\
\text { question }\end{array}$ & $\mathrm{CQ}$ & $\begin{array}{l}\text { Questions that require confirmation in the form of 'yes or } \\
\text { no'; 'agree or disagree'; 'volunteer or not volunteer' }\end{array}$ & $\begin{array}{l}\text { Do you know an elephant? (CS3) } \\
\text { Is that clear? (CS2) }\end{array}$ & $23.6 \%$ \\
\hline Numerical question & NQ & $\begin{array}{l}\text { Questions that require students to make simple } \\
\text { mathematical operations and provide their responses in } \\
\text { the form of number }\end{array}$ & $\begin{array}{l}\text { - How much is the product? (CS1) } \\
\text { - How much kilogram is a hundred gram? } \\
\text { (CS3) }\end{array}$ & $7 \%$ \\
\hline $\begin{array}{l}\text { Organizational } \\
\text { question }\end{array}$ & $\mathrm{OQ}$ & $\begin{array}{l}\text { Questions posed for the purpose of organizing or } \\
\text { controlling }\end{array}$ & $\begin{array}{l}\text { - Did you listen to her? (CS1) } \\
\text { - What are you writing? (CS1) }\end{array}$ & $4.2 \%$ \\
\hline Informative questions & IQ & $\begin{array}{l}\text { Questions in which their answers are available in the } \\
\text { numerical problem under consideration. }\end{array}$ & $\begin{array}{l}\text { - How much is the force? (CS1) } \\
\text { - How much is the area? (CS2) }\end{array}$ & $7 \%$ \\
\hline
\end{tabular}

interventions to create conceptual development through open questions, formative feedback and encouragement of students to reflect and clarify their thinking were weak.

Questioning, which was the dominant type of teachers' intervention, was observed throughout the whole sessions. Even if many oral questions were posed throughout the lessons, they were meant neither to measure the students' understanding nor to scaffold the students' engagement in meaning-making. In addition to questioning, sharing of ideas and reviewing were among the interventions teachers made to facilitate students' learning. The sharing of ideas was mainly observed when the groups reflect the result of their discussion to the whole class. Reviewing, which refers to revising or reminding of knowledge from the previous lessons as described in some places earlier, was observed in the introduction session of the lesson.

The teachers' attempt to encourage students' involvement in interaction through open questions such as 'How' and 'Why' question was very limited. The following groups of questions were examples of questions frequently asked by the teachers in the three phases.

\section{Phase-one}

1. What is pressure? (school 2 and school 3 )

2. What is force? (school $\mathbf{1}$ and school 2)

3. What is matter? (school $\mathbf{1}$ )

\section{Phase-two}

1. What is the SI unit of pressure? (school 2)

2. What is the symbol of area? (school 2)

3. Does liquid have a definite shape? (school 3)

\section{Phase-three}

1. Who can define pressure? (school 2)

2. What is simple machine? (school $\mathbf{1})$

3. What is a lever? (school 1)

\section{Teacher's Oral Questions with Respect to Functions}

A qualitative analysis was made to classify teachers' questions with respect their functions. The functional analysis of teachers' questions was made on 216 questions. Except few questions including "why did you get different answers?", "What did you say?" and "why did the answer become negative?", which were asked only once in their respective lessons, all other questions were collated so that those with similar purposes were grouped together to form themes. From the analysis of the questions, seven groups of questions were emerged. These are Descriptive Questions (DQ), Leading Questions (LQ), Procedural Questions (PQ), Conformational Questions (CQ), Numerical Questions (NQ), Organizational Questions (OQ) and Informative Questions (IQ). The frequency of the questions was found to be different among the categories with descriptive questions having the highest and organizational questions the lowest frequency. Table 4 presents the functional categories of the teachers' oral questions, respective descriptions, examples and percentage of the questions under each category.

The variance in the number of questions under each functional category might be interpreted with respect to the nature of classroom practices. As shown in Table 4, questions that require students to define physics terms, describe concepts, list items, and provide brief answers were asked more frequently (37.5\%). This implies that the teachers' oral questions were targeted at encouraging low-level cognition, and the contents of the classroom utterances were turned towards the "description" end of the "description-explanation-generalization" dimension of the Mortimer and Scott's framework (Mortimer \& Scott, 2003). 
From the identified functional categories listed in Table 4, the procedural, numerical and informative questions together (about $43 \%$ of the categories), which share $28 \%$ of the teachers' questions, were related to solving and computing of numerical problems. Moreover, questions that encourage higher order cognition were rarely asked by the teachers. For example, from the 216 teachers' questions, only three questions demanded the students to provide reasons. This in turn verified that teachers gave more emphasis on solving numerical problems and description of facts rather than developing and checking the students' conceptual understanding.

\section{DISCUSSIONS}

This study set out with the aims of exploring the teacher-student interaction and determining the aspects of the interaction that constrain the success of dialogic teaching in physics classrooms. The analysis was made based on five features of teacherstudent interaction including teaching purposes, content of the interaction, communicative approach, pattern of discourse and teacher interventions (Mortimer \& Scott, 2003).

From the analysis of the teacher-student interaction, it is inferred that the culture of physics teaching and learning in the classroom was characterized by reminding of knowledge from previous lessons, describing and providing the definitions of physics terms, solving numerical problems and describing the relationship between physical quantities in the form of mathematical equations. The teacher-student interaction was mainly facilitated by the teacher's oral questions which were simple, straightforward, and that require recalling of information. As a consequence of the process of question-answer-reaction sequence, the classrooms became interactive and characterized by two distinctive patterns of discourse, including InitiationResponse-Evaluation (I-R-E) and Initiation-Discussion/computation-Response-Evaluation (I-D-C-R-E) type of interaction patterns. Focusing on defining and describing contents in the curriculum rather than working on the diverse views of students made the classroom more authoritative.

However, unlike the characteristics demonstrated by the existing physics classrooms, in dialogic teaching, more attention is required to be given to promote classroom interactions that help students share ideas and construct meaning collectively (Lyle, 2008) and to provide students with the opportunity to analyse and evaluate the perspectives of others so as to develop their conceptual understanding (Alexander, 2006). In dialogic teaching, the classroom environment should be in a manner that it supports the exchange of ideas among students and teachers, the building of ideas upon others, evaluation of ideas, provision of justifications, free and equal participation of students in classroom dialogue (Lefstein \& Snell, 2014).

The roles that teachers play are very crucial in dialogic teaching. The quality of the teachers' questions, the nature of classroom activities they designed, the teachers' management of small group organizations, their assessment strategies and the manner of their feedback are among the necessary classroom practices to be considered by teachers who need to employ dialogic teaching effectively in their classrooms (Bathgate et al., 2015). The potential of teacher's questions to encourage productive classroom discourse and learning lays on the quality of the questions (Lee \& Kinzie, 2012). A higher level of cognition in classroom teaching is facilitated by asking useful questions (Chin, 2007; Lemke, 1990; Mortimer \& Scott, 2003) that should be framed in a manner to explore the students' thinking, encourage them to elaborate and justify their claims and to help them construct knowledge through effective questions (Chin, 2007).

However, in this study, the findings indicated that most of the teacher's oral questions were developed in a manner to elicit short 'right answers' which limited the students' contribution to the development of the classroom discourse (Mortimer \& Scott, 2003). The purpose of the questions seemed to evaluate the students' knowledge which is a characteristic of traditional lessons rather than examining their understanding (Chin, 2006). The use of such questions made the classroom interaction to be monologic, which provided few opportunities for students to voice their perspectives (Molinari, Mameli, \& Gnisci, 2013) and often limited to recalling of information given in the form of single-word response (Viiri \& Saari, 2006).

Concerning the teacher's feedback, scholars suggest that the teacher's reaction to the students' responses determines the nature of classroom communication (Chin, 2006; Mortimer \& Scott, 2003). This is because it is the feedback that determines the next cycle in the teaching and learning spiral and results in sustained classroom interaction (Wells, 1993). In particular, the 'teachers' initial questioning and follow-up strategies can serve as scaffolding to support students' construction of conceptual understandings of science concepts" (Smart \& Marshal, 2013, p. 251). It is also claimed in the literature that the effectiveness of the feedback to students' responses is measured by whether or not the feedback encourages productive thinking and elicits different viewpoints of the students (Chin, 2006). In this regard, teachers can explore students' thinking by providing elaborative feedback that initiates further responses from the students (Chin, 2006; Mortimer \& Scott, 2003). However, the findings of this study indicated that in the existing classroom culture of physics teaching and learning, the teachers' feedbacks were evaluative such as accepting correct responses and ignoring incorrect ideas and responses. The evaluative nature of the teachers' feedback limits the expansion of the classroom dialogue, which in turn resulted in authoritative classroom communication.

The existence of the distinct patterns of classroom discourse in the current study lays mainly on the question and answer sequence mostly used in the classrooms. The interaction sequence initiated by teachers' oral questions followed a general pattern of the Initiation-Response-Evaluation (I-R-E) sequence which Lemke (1990) named a triadic dialogue. The triadic dialogue often perceived to have a restrictive effect on students' thinking (Chin, 2006; Viiri \& Saari, 2006) and it does not encourage the participation of students (Lemke, 1990).

In order to engage students in an exploratory talk, which is the ultimate goal of dialogic teaching, teachers need to encourage students through thought-provoking questions and allow them to share their knowledge and experiences (King, 2002). Teachers should use such questions that encourage students to reflect their thoughts, reasons, understanding and offer opportunities for 
students to be involved in sustained interaction (Mortimer \& Scott, 2003). Although scholars emphasise the importance of working on students' thoughts and their viewpoints for productive dialogue (Mercer \& Littleton, 2007; Mortimer \& Scott, 2003), it was observed in the current study that teachers were not in a position to use the students' ideas for the co-construction of knowledge. Instead, they failed to appropriately support and use classroom talk effectively to enhance their learning. This finding is in agreement with the findings of previous studies which found that teachers' interventions are focussed on procedures, and their feedback is typically evaluative (Chiu, 2004; Webb et al., 2009).

The current study has considered only one aspect of classroom culture (the teacher-student interaction). Hence, in order to have comprehensive understanding on the effect of classroom culture on dialogic teaching, further study is needed to examine other features of classroom culture such as student-student, student-content and teacher-content interactions. Moreover, in this study, a framework developed by Mortimer and Scott (2003) was used to characterize the teacher-student interaction. So, using a more updated framework may refine the findings of this study.

\section{CONCLUSIONS}

The results of this investigation show that the teachers' attempt to develop the students' understanding of physics knowledge in the existing classroom culture seemed to be poor. The teacher-student interaction was characterized by an ineffective teacher support and intervention, use of low-level questions as the main intervention strategy, focussing on description and definitions of terms in the curriculum, non-supportive classroom environment for dialogic interaction, Initiation-Response-Evaluation (I-R-E) and Initiation-Discussion/computation-Response-Evaluation (I-D/C-R-E) as distinct patterns of classroom discourse. The study also showed that these aspects of teacher-student interaction contradict the principles that dialogic teaching encourages classroom communication that help students to share ideas and construct collective meanings (Lyle, 2008) and that dialogic teaching provides the students with the opportunity to be engaged in analysing and evaluating of other's point of views (Alexander, 2006). These findings enhance our understanding of the issues related to teacher-student interaction that constrain the implementation of dialogic teaching.

\section{IMPLICATION OF THE STUDY}

One of the most important implications of this study is for professional development of physics teachers who need to employ dialogic teaching in their classrooms. In this study it was shown that the existing classroom culture of physics teaching and learning is characterized by the use of low level questions and unproductive teacher support which resulted in authoritative classroom communication and a triadic type of classroom discourse. This kind of classroom discourse is less effective to engage students in an exploratory talk and has a restrictive effect on students' learning (Chin, 2006; Lemke, 1990; Virri \& Saari, 2006).

Although dialogic communication would not be expected from the existing physics classroom as teachers had no awareness about dialogic teaching, this study has explored the aspects of teacher-student interaction that potentially influence the implementation of dialogic teaching in didactic classroom environments. Therefore, before beginning implementing dialogic teaching in their classrooms, teachers should be involved in purposefully designed professional development programs which take the constraints into account.

Author contributions: All authors have sufficiently contributed to the study, and agreed with the results and conclusions.

Funding: No funding source is reported for this study.

Declaration of interest: No conflict of interest is declared by authors.

\section{REFERENCES}

Abdela, B., \& Kassahun, M. (2010). Qualitative exploration on the application of student-centred learning in mathematics and natural sciences: The case of selected general secondary schools in Jimma, Ethiopia. Ethiopian Journal of Education and Science, 6(1), 41-58. https://doi.org/10.4314/ejesc.v6i1.65380

Alexander, R. (2001). Culture and pedagogy. International Comparisons in Primary Education. Blackwell.

Alexander, R. (2006). Towards dialogic teaching: Rethinking classroom talk (3rd Ed.). Dialogs.

Aufschnaiter, C., Erduran, S., Osborne, J., \& Simon, S. (2007). Argumentation and learning of science. In R. Pinto \& D. Couso (Eds.), Contribution from science education research (pp. 377-388). Springer Dordrecht Heidelberg. https://doi.org/10.1007/978-14020-5032-9-29

Bathgatea, M., Crowellb, A., Schunna, C., Cannadyc, M., \& Dorph, R. (2015). The learning benefits of being willing and able to engage in scientific argumentation. International Journal of Science Education, 37(10), $1590-1612$. https://doi.org/10.1080/09500693.2015.1045958

Boyd, M. P., \& Markarian, W. C. (2015). Dialogic teaching and dialogic stance: Moving beyond interactional form. Research in the Teaching of English, 49(3), 272-296.

Calcagni, E., \& Lago, L. (2018). The three domains for dialogue: A framework for analysing dialogic approaches to teaching and learning. Learning, Culture and Social Instruction, 18, 1-12. https://doi.org/10.1016/j.lcsi.2018.03.001 
Chin, C. (2006). Classroom interaction in science: Teacher questioning and feedback to students' responses. International Journal of Science Education, 28(11), 1315-1346. https://doi.org/10.1080/09500690600621100

Chin, C. (2007). Teacher questioning in science classrooms: Approaches that stimulate productive thinking. Journal of Research in Science Teaching, 44(6), 815-843. https://doi.org/10.1002/tea.20171

Chiu, M. M. (2004). Adapting teacher interventions to student needs during cooperative learning: How to improve student problem solving and time on-task. American Educational Research Journal, 41(2), 365-399. https://doi.org/10.3102/00028312041002365

Daniel, D. (2004). Observations and reflections of the higher education teachers on the quality of teaching and learning in higher education in Ethiopia. The Ethiopian Journal of Higher Education, 1(1), 63-68.

Derebssa, D. S. (2006). Tension between traditional and modern teaching-learning approaches in Ethiopian primary schools. Journal of International in Education, 19(1), 123-140.

Garcia-Mile, M., \& Anderson, C. (2007). Cognitive foundation of learning argumentation. In S. Erduran \& M. P. Jimenez-Aleixandre (Eds.), Argumentation in Science Education (pp. 29-45). Springer Dordrecht Heidelberg. https://doi.org/10.1007/978-1-40206670-2_2

Gillies, R. M. (2017). Promoting academically productive student dialogue during collaborative learning. International Journal of Educational Research, 97, 200-209. https://doi.org/10.1016/j.ijer.2017.07.014

Graham, M., Milanowski, A., \& Miller, J. (2012). Measuring and promoting inter-rater agreement of teacher and principal performance ratings. http://files.eric.ed.gov/fulltext/ED532068.pdf

Howe, C., \& Mercer, N. (2007). Children's social development, peer interaction and classroom learning [Primary Review], University of Cambridge, Faculty of Education.

King, A. (2002). Structuring peer interaction to promote high-level cognitive processing. Theory into Practice, $41,33-40$. https://doi.org/10.1207/s15430421tip4101_6

Lee, Y., \& Kinzie, M. B. (2012). Teacher question and student response with regard to cognition and language use. Instructional Science, 40(6), 858-874. https://doi.org/10.1007/s11251-011-9193-2

Lefstein, A., \& Snell, J. (2014). Better than best practice: Developing teaching and learning through dialogue. Routledge. https://doi.org/10.4324/9781315884516

Lemke, J. L. (1990). Talking science. Language, learning and values. Ablex.

Lyle, S. (2008). Dialogic teaching: Discussing theoretical contexts and reviewing evidence from classroom practice. Language and Education, 22(3), 222-240. https://doi.org/10.1080/09500780802152499

McNeil, K., Katsh-Singer, R., Geonzlez-Howard, M., \& Loper, S. (2016). Factors impacting teachers' argumentation instruction in their science classrooms. International Journal of Science Education, 38(12), $2026-2046$. https://doi.org/10.1080/09500693.2016.1221547

Mekbib, A. (2015). Peer tutors led argumentation and Ethiopian pre-service teachers' physics content achievement and physics epistemology (Unpublished doctoral dissertation). Addis Ababa University, Addis Ababa, Ethiopia.

Mekbib, A., Kind, V., Mesfin, B., Kassa, M., Mulugeta, A., Kind, P., \& Rajab, T. (2019). The knowledge gap between intended and attained curriculum in Ethiopian teacher education: identifying challenges for future development. Compare: $A$ Journal of Comparative and International Education, 1-18. https://doi.org/10.1080/03057925.2019.1593107

Mercer, N., \& Howe, C. (2012). Explaining the dialogic processes of teaching and learning: The value and potential of sociocultural theory. Learning, Culture and Social Interaction, 1(1), 12-21. https://doi.org/10.1016/j.lcsi.2012.03.001

Mercer, N., \& Littleton, K. (2007). Dialogue and the development of children's thinking. Routledge. https://doi.org/10.4324/9780203946657

Molinari, L., Mameli, C., \& Gnisci, A. (2013). A sequential analysis of classroom discourse in Italian primary schools: The many faces of the IRF pattern. British Journal of Educational Psychology, 83, 414-430. https://doi.org/10.1111/j.2044-8279.2012.02071.x

Mortimer, E. F., \& Scott, P. H. (2003). Meaning making in secondary science classroom. Open University Press.

Muhonen, H., Rasku-Puttonen, H., Pakarinen, E., Poikkeus, A.-M., \& Lerkkanen, M.-K. (2017). Knowledge-building patterns in educational dialogue. International Journal of Educational Research, 81, 25-37. https://doi.org/10.1016/j.ijer.2016.10.005

Osborne, J. (2012). The role of argument: Learning how to learn in school science. In B. J. Fraser, K. J. Tobin, \& C. J. McRobbie (Eds.). Second international hand book of science education (pp. 933-949). Springer Dordrecht Heidelberg. https://doi.org/10.1007/978-1-4020-9041-7_62

Osborne, J., Erduran, S., \& Simon, S. (2004). Enhancing the quality of argumentation in school science. Journal of Research in Science Teaching, 41, 994-1020. https://doi.org/10.1002/tea.20035

Rojas-Drummond, S., Maine, F., Alarcóna, M., Laura Trigoa, A., José Barrera, M., Mazón, N., Vélez, M., \& Hofmann, R. (2017). Dialogic literacy: Talking, reading and writing among primary school children. Learning, Culture and Social Interaction, 12, 45-62. https://doi.org/10.1016/j.lcsi.2016.09.005

Rojas-Drummond, S., Torreblanca, D., Pedraza, H., Velez, M., \& Guzman, K. (2013). Dialogic scaffolding: Enhancing learning and understanding in collaborative contexts. Learning, Culture and Social Interaction, 2, 11-21. https://doi.org/10.1016/j.lcsi.2012.12.003 
Smart, J. B., \& Marshall, J. C. (2013). Interactions between classroom discourse, teacher questioning, and student cognitive engagement in middle school science. Journal of Science Teacher Education, 24, 249-267. https://doi.org/10.1007/s10972-0129297-9

Tadesse, M. (2017). Dialogic argumentation as pedagogy: Impact on preservice physics teachers' conceptual understanding of mechanical waves (Unpublished doctoral dissertation). Addis Ababa University, Addis Ababa, Ethiopia.

Viiri, J., \& Saari, H. (2006). Teacher talks pattern in science lessons: Use in teacher education. Journal of Science Teacher Education, 17, 347-365. https://doi.org/10.1007/s10972-006-9028-1

Webb, N., Franke, M. L., De, T., Chan, A. G., Freund, D., Shein, P., \& Melkonian, D. K. (2009). 'Explain to your partner': Teachers' instructional practices and students' dialogue in small groups. Cambridge Journal of Education, 39(1), 49-70. https://doi.org/10.1080/03057640802701986

Wells, G. (1993). Re-evaluating the IRF sequence: A proposal for the articulation of theories of activity and discourse for the analysis of teaching and learning in the classroom. Linguistics and Education, 5(1), 1-37. https://doi.org/10.1016/S0898-5898(05)800014

Wilkinson, I. I. G., Reznitskaya, A., Bourdage, K., Oyler, J., Glina, M., Drewry, R., Kim, M.-Y., \& Nelson, K. (2017). Toward a more dialogic pedagogy: Changing teachers' beliefs and ractices through professional development in language arts classrooms. Language and Education, 31(1), 65-82. https://doi.org/10.1080/09500782.2016.1230129 